Disponível em:

http://editora.unoesc.edu.br/index.php/race

RACE, Joaçaba, v. 17, n. 1, p. 283-312, jan./abr. 2018

\title{
DINÂMICA DA INFLAÇÃO E POLÍTICA MONETÁRIA NO BRASIL: UMA LEITURA PÓS-KEYNESIANA COM USO DA METODOLOGIA DE VETORES AUTORREGRESSIVOS (VARS)
}

Inflation dynamics and monetary policy in Brazil: a post-keynesian reading using the SelfRegressive Vector (VAR)

Larissa Naves de Deus

E-mail: larissand6@hotmail.com

Mestre em Economia pela Universidade Federal de Uberlândia; Doutoranda em

Economia na Universidade Federal de Uberlândia.

Endereço para contato: Avenida João Naves de Ávila, 2121, Bloco J, 38408-144,

Uberlândia, Minas Gerais, Brasil. 


\section{Resumo}

Muitos países, a partir da década de 1990, passaram a utilizar o Regime de Metas de Inflação (RMI) como regime de política monetária, inclusive o Brasil, que o adotou em 1999. Entretanto, há inúmeras críticas ao modo de funcionamento desse regime, além da análise das consequências de seu uso à dinâmica macroeconômica dos países. No contexto do RMI, consideram-se os desvios do produto de seu nível natural à causa do aumento generalizado dos preços, e, assim, utiliza-se a taxa de juros como instrumento de política monetária. Neste trabalho, seguindo-se uma perspectiva pós-keynesiana, que tece críticas a esse regime, inclusive ao considerar que a inflação é um fenômeno multicausado, teve-se como objetivo investigar empiricamente quais são as variáveis explicativas das causas da inflação brasileira no período pós-RMI, especificamente, de 2003 a 2016. Assim, objetiva-se, inclusive, debater se a política monetária baseada nesse regime é condizente com o funcionamento de economias monetárias. Para tanto, além da revisão bibliográfica como método de procedimento, em que se busca apresentar as diferenças teóricas do chamado Novo Consenso Macroeconômico, que dá sustentação ao RMI, e a escola pós-keynesiana, neste trabalho utiliza-se a metodologia econométrica de Vetores Autorregressivos (VARs), que permite analisar inter-relações entre múltiplas variáveis, de modo a se auferirem as variáveis relevantes na explicação da dinâmica de preços no Brasil no período recente. Os resultados encontrados apontam que os fatores do lado da oferta da economia explicam em boa medida a dinâmica inflacionária brasileira no período analisado, indicando, assim, a fragilidade em se utilizar apenas a taxa de juros como instrumento de política monetária.

Palavras-chave: Regime de Metas de Inflação. Pós-keynesianos. Inflação.

\section{Abstract}

Many countries started to use the Inflation Target Regime (RMI) as a monetary policy regime, including Brazil, which adopted it in 1999. However, there are innumerable criticisms of the way this regime operates, besides the analysis of the consequences of its use to the macroeconomic dynamics of the countries. In the context of the RMI, the deviations of the product from its natural level are taken as the cause of the generalized increase of prices, and thus, the interest rate is used as a monetary policy instrument. This work, following a postkeynesian perspective, which criticizes this regime, including considering that inflation is a multi-caused phenomenon, aims to investigate empirically what are the explanatory variables of the causes of brazilian inflation in the post-RMI period, specifically from 2003 to 2016. Thus, it is also intended to discuss whether the monetary policy based on this regime is consistent with the operation of monetary economies. For this, in addition to the bibliographic review as a procedure method, which seeks to present the theoretical differences of the so-called New Macroeconomic Consensus, which gives support to the RMI, and the post-keynesian school, this work uses the econometric methodology of Autoregressive Vectors (VAR), which allows 
analyzing interrelations between multiple variables, in order to obtain the relevant variables in the explanation of the price dynamics in Brazil in the recent period. The results show that the factors on the supply side of the economy largely explain the brazilian inflationary dynamics in the period analyzed, thus indicating the fragility of using only the interest rate as a monetary policy instrument.

Keywords: Inflation Target Regime. Post-keynesians. Inflation.

\section{INTRODUÇÃO}

O Regime de Metas de Inflação (RMI) passou a ser o regime de política monetária de muitos países a partir da década de 1990, adotado pelo Brasil em 1999. Tendo como base teórica os pressupostos do chamado Novo Consenso Macroeconômico (NCM), esse regime tem como objetivo principal a busca pela estabilidade de preços, que deve ser perseguida pela Autoridade Monetária (AM), dispondo do manejo da taxa de juros como instrumento para tal. Assim, os demais objetivos de política econômica possuem caráter subordinado, de modo que os desdobramentos sobre o nível de emprego e produto da economia são subsidiariamente considerados.

A partir dos pressupostos que dão sustentação ao regime, como a neutralidade da moeda e a ineficiência da política monetária afetarem variáveis reais, há o diagnóstico de que o aumento do nível de preços ocorre em decorrência de alterações nas variáveis do lado da demanda da economia. Por isso de o único instrumento de política monetária utilizado no contexto do RMI ser a taxa de juros, uma vez que a elevação dessa taxa, por exemplo, serve para deprimir os componentes da demanda, fazendo repercutir, consequentemente, a diminuição dos preços.

Entretanto, a corrente pós-keynesiana tece críticas a esse regime, primeiro, por não considerá-lo adequado ao funcionamento de economias monetárias, em que a moeda importa - o que realça os diferentes pressupostos pelos quais essas escolas de pensamento partem para enxergarem o modo de funcionamento de economias capitalistas -, e, também, por entenderem que a inflação é um processo causado por muitos fatores, devendo-se incluir mais componentes em sua explicação. Fatores relacionados ao lado da oferta da economia são relevantes para explicar a inflação, como formação de preços, estrutura de mercado, conflito distributivo, entre outros.

Nesse sentido, o objetivo com este artigo foi o de verificar empiricamente, tendo como base o referencial teórico pós-keynesiano, qual a dinâmica de preços no Brasil pós-RMI. Busca-se, assim, entender as variáveis relevantes na explicação da inflação, para, com isso, analisar a maior convergência da realidade com o modelo 
teórico que sustenta o RMI ou a teoria pós-keynesiana, que tece inúmeras críticas ao modo de condução da política monetária dentro desse contexto. Embora a literatura econômica tenha avançado em termos da busca pelas causas da inflação, e, consequentemente, dos instrumentos mais adequados para contê-la, o diferencial neste trabalho está em buscar empiricamente a dinâmica de preços no Brasil, para, então, discutir um regime de política monetária alternativo ao vigente, com base na visão de Keynes e nos avanços feitos pelos autores pós-keynesianos acerca de uma política voltada à estabilidade do nível de preços, que leve em conta os muitos fatores causais da inflação, além do nível de produto e emprego da economia.

Dessa forma, este artigo se estrutura em três seções, além desta breve introdução e das considerações finais. A primeira seção analisa a abordagem teórica que sustenta o RMI, assim como seu modo de funcionamento. A segunda seção contempla a análise dos aspectos gerais da corrente de pensamento pós-keynesiana, suas críticas ao RMI, além da abordagem acerca dos tipos de inflação existentes e os possíveis instrumentos de política monetária a serem utilizados. A terceira seção apresenta a metodologia empírica de Vetores Autorregressivos (VARs) a ser utilizada, assim como os principais resultados encontrados da dinâmica de preços brasileira.

\section{O NOVO CONSENSO MACROECONÔMICO E O REGIME DE METAS DE INFLAÇÃO}

O RMI tem como bases teóricas os fundamentos do chamado Novo Consenso Macroeconômico (NCM), que contempla pontos convergentes de política macroeconômica das correntes Novo Clássica e Novo Keynesiana. Da escola Novo Clássica assume-se a otimização intertemporal, além das expectativas racionais por parte dos agentes, ao passo que da escola Novo Keynesiana, o NCM incorpora a competição imperfeita e a rigidez de preços. Assim, apenas os preços são ajustados de modo a se garantir a igualdade entre produto potencial e produto efetivo, já que no curto prazo prevalece o teor Novo Keynesiano, correlacionando o nível de produto real com movimentos da demanda agregada, enquanto que no longo prazo, a partir do novo classicismo, assume-se a neutralidade da moeda e a ausência de correlação entre demanda e produto real (MOREIRA, 2012).

Para os autores Novo Clássicos, os agentes são racionais e conseguem antecipar qualquer intervenção do Governo, de modo que tais ações geram efeitos neutros. No que se refere à política monetária, se a AM aumenta a oferta de moeda, os agentes, racionais que são, sabem que o resultado trará aumento da inflação, como prega a 
Teoria Quantitativa da Moeda, ${ }^{1}$ e, assim, antecipam-se elevando preços e salários, sem alterações nos níveis de emprego e produto. Nesse sentido, apenas se a AM age de maneira a surpreender os agentes, sua política resultaria em efeitos reais. "Todavia, tudo que o governo consegue na prática é confundir os agentes e provocar distorções no curto prazo, em função dos erros de previsão.” (FREITAS, 2006, p. 271). Além disso, como os agentes possuem expectativas racionais, aprenderiam com os erros, e os efeitos de curto prazo de tal política se dissipariam. Por isso da proposição dessa escola de que a AM deve se guiar por meio de regras claras e não por meio de políticas discricionárias, para além da tese de independência do Banco Central (BC).

Já para os autores da escola Novo Keynesiana, ao contrário dos Novo Clássicos, a política monetária afeta as variáveis reais no curto prazo, em razão, sobretudo, das imperfeições de mercado existentes, como a rigidez de preços e salários, concebendo, assim, a moeda neutra apenas no longo prazo (OREIRO; NEVES, 2008).

Dessa forma, no NCM o RMI seria o melhor regime de política monetária a ser adotado, tendo como objetivo o combate à inflação. O objetivo único de preservar a estabilidade de preços decorre da ideia de que um ambiente com nível de preços estável propicia níveis de eficiência mais elevados, estando relacionados, por exemplo, à melhor alocação dos fatores de produção e a melhores decisões de investimento por parte dos agentes.

Vale destacar que o componente foward looking das expectativas dos agentes otimizadores no RMI faz com que as funções a serem maximizadas, expressas a seguir, sejam intertemporais. Por conta das expectativas racionais os ajustes dos mercados podem ocorrer de maneira lenta, admitindo, assim, a influência da política monetária sobre variáveis reais no curto prazo, ressaltando que “é tal lenta a interação que torna efetivo o trade-off de curto prazo entre inflação e desemprego previsto pela Curva de Phillips” (TERRA, 2013, p. 2, grifo do autor). Mas, no longo prazo, as va-

\footnotetext{
${ }^{1}$ A TQM é a forma pela qual os autores clássicos explicam a variação dos preços na economia, que ocorre de acordo com a quantidade de moeda em circulação, uma vez que a velocidade da moeda é estável e a renda é dada a cada período. Nessa abordagem, a moeda funciona apenas como meio de troca, o que demonstra seu caráter de neutralidade. O postulado da manutenção constante da velocidade-renda da moeda implica inexistência de entesouramento, ressaltando a ligação entre a TQM e a Lei de Say, uma vez que esta pressupõe que o mesmo processo de produção que cria os produtos (oferta) gera rendas, sendo que estas se transformam em demanda pela compra de outros produtos. Assim, seria irracional incorrer no desprazer do trabalho para entesourar recursos. Como consequência, a moeda é neutra, uma vez que não é um objeto desejado para reservar valor ao longo do tempo, apenas para facilitar as trocas entre aquilo que os agentes produziram.
} 
riáveis reais são afetadas apenas pelos componentes do lado da oferta da economia, ressaltando a neutralidade da moeda.

Pode-se sustentar, também, que se a AM conta com credibilidade, os agentes creem que ela está comprometida pela busca de seu objetivo - a meta de inflação - e, assim, as expectativas de inflação futura dos agentes caem, o que colabora para que haja a convergência da inflação observada para a sua meta. Para além, nesse caso, o aumento da taxa de juros para conter o processo inflacionário é menor que no caso em que a AM age de maneira discricionária (OREIRO; NEVES, 2008).

Dessa forma, de maneira a sintetizar o argumento, Mendonça (2002) aponta que o RMI envolve cinco elementos básicos em seu funcionamento: anúncio público de metas para a inflação no médio prazo; compromisso institucional da AM com a estabilidade de preços como o objetivo prioritário da política monetária; informações ao público do comportamento das principais variáveis responsáveis pela estratégia; transparência da estratégia da política monetária; e criação de mecanismos garantidores que a AM seja comprometida na busca dos objetivos inflacionários.

A partir desses elementos, pode-se perceber que o RMI busca uma maior transparência na condução da política monetária, sendo que os canais de comunicação entre a AM e os agentes econômicos fazem parte do arcabouço do regime, o que resulta em redução da incerteza desses últimos quanto ao comportamento futuro da inflação. Para além, um BC com transparência e credibilidade, como visto anteriormente pode eliminar o problema inflacionário sem maiores custos sociais. Assim, “essas metas [inflacionárias] podem coordenar a formação de expectativas inflacionárias dos agentes e a fixação de salários e preços, atuando, assim, como uma âncora nominal tanto para a inflação atual como para as expectativas futuras.” (CARRARA; CORREA, 2012, p. 445).

Conforme destacam Arestis e Sawyer (2003), o modelo proposto pelo NCM pode ser expresso pelas seguintes equações:

$$
\begin{gathered}
Y_{t}^{g}=a_{0}+a_{1} Y_{t-1}^{g}+a_{2} E_{t}\left(Y_{t-1}^{g}\right)-a_{3}\left[R_{t}-E_{t}\left(p_{t+1}\right)\right]+s_{1} \\
p_{t}=b_{1} Y_{t}^{g}+b_{2} p_{t-1}+b_{3} E_{t}\left(p_{t-1}\right)+s_{2},\left(c o m b_{2}+b_{3}=1 b_{2}+b_{3}=1\right. \\
R_{t}=R R^{*}+E_{t}\left(p_{t+1}\right)+c_{1} Y_{t-1}^{g}+c_{2}\left(p_{t-1}-p^{T}\right)
\end{gathered}
$$


Tem-se que $\mathrm{Y}_{\mathrm{t}}^{\mathrm{g}} \mathrm{Y}_{\mathrm{t}}^{\mathrm{g}}$ representa o gap do produto; $\mathrm{RR}$ a taxa de juros nominal; pp a taxa de inflação; $p^{T} p^{T}$ a meta de inflação; $R R^{*} R R^{*}$ a taxa de juros real de equilíbrio; $\mathrm{s}_{1} \mathrm{~s}_{1}$ os erros estocásticos e $\mathrm{E}_{\mathrm{t}} \mathrm{E}_{\mathrm{t}}$ as expectativas no tempo $\mathrm{t}$.

A Equação 1 representa a demanda agregada com o gap do produto dependendo tanto de seu valor passado quanto da expectativa de seu valor no futuro e com a taxa de juros real. "Cabe ressaltar que não existem atividades governamentais e que

o parâmetro $\mathrm{a}_{3} \mathrm{a}_{3}$ corresponde à elasticidade intertemporal de substituição." (OREIRO; NEVES, 2008, p. 114). A Equação 2 representa a Curva de Phillips, determinada pela inflação passada e pela expectativa de inflação além do nível de produto atual. Já a Equação 3 corresponde à regra de política monetária, equivalente a uma Regra de Taylor, em que a taxa de juros nominal definida pela AM é baseada na taxa de inflação esperada, no gap do produto passado, no desvio da inflação de sua meta, além da taxa de juros real de equilíbrio de longo prazo.

A partir da interação dessas três equações, tem-se a dinâmica do modelo RMI, sendo a taxa de juros o instrumento que a AM utiliza para atingir seu objetivo, qual seja, manter estável o nível de preços. Dessa forma, caso a inflação observada esteja acima da meta estipulada, cabe à AM aumentar a taxa nominal de juros, por meio de sua função de reação (Equação 3). No curto prazo, o efeito do aumento da taxa nominal de juros ocorre sobre a demanda agregada, representada pela Equação 1, sendo que a magnitude desse efeito é captada pela elasticidade intertemporal de substituição, em que "quanto maior for esse parâmetro, maior será o sacrifício da demanda hoje, em prol de uma demanda maior no futuro.” (OREIRO; NEVES, 2008, p. 115). Por fim, o resultado final é observado mediante a Equação 2, em que se espera um nível de inflação menor.

Como enfatizado por Arestis e Sawyer (2003), o RMI enfoca o papel da política monetária para combater a inflação de demanda, sendo que, como observado pela Equação 2, a inflação de custos não é captada pelo modelo. Por isso de o único instrumento da AM ser a taxa de juros nominal, uma vez que essa variável oferece à política monetária flexibilidade e eficiência para controlar o nível de demanda agregada (TAYLOR, 1993 apud Terra, 2013). Quando a inflação é causada por choques de oferta, a política monetária busca amortecê-la sem que seja necessário aumentar os juros, seja via bandas de inflação, o que confere maior flexibilidade ao RMI, seja 
pelo espaço de tempo necessário à convergência da inflação à meta (SILVA; TERRA; VIANA, 2014, p. 4).

Além do efeito direto do aumento dos juros sobre a demanda agregada, em uma economia aberta, com livre mobilidade na conta capital e financeira e comercial, a elevação dos juros provoca um influxo de capitais no mercado cambial, uma vez que os ativos domésticos ficam mais atrativos em relação aos externos, o que pode implicar valorização do câmbio. Essa valorização pode, por um lado, favorecer a complementaridade da oferta doméstica de maneira menos custosa em relação à produção internacional e, por outro lado, causar um choque positivo de oferta em razão da redução dos custos de produção, via pass-through. Assim, "sob os princípios do NCM, a taxa de câmbio de equilíbrio será encontrada tão logo os fluxos de capital no mercado cambial se ajustem às condições de curto prazo.” (SILVA; TERRA; VIANA, 2014, p. 5).

A adoção do RMI ocorre pela observância dessas características, de cunho teórico, anteriormente analisadas, mas o desenho institucional pode variar a depender do país que se observe. No Brasil, o regime foi adotado em 1999, no contexto de fortes desvalorizações do real, em substituição ao regime de âncora cambial até então vigente.

O Decreto n. 3.088, de 21 de junho de 1999, estabelece a sistemática do novo regime de política monetária no Brasil, sendo elencados, a seguir, seus principais pontos: as metas seriam representadas por variações anuais de índice de preços de ampla divulgação; as metas e seus intervalos de tolerância (bandas) seriam fixados pelo Conselho Monetário Nacional (CMN); ao BC do Brasil cabia executar as políticas necessárias para cumprimento das metas fixadas; o índice de preços a ser adotado seria escolhido pelo CMN, mediante proposta do Ministro da Fazenda; considera-se cumprida a meta quando a variação acumulada da inflação, relativa ao período de janeiro a dezembro de cada ano/calendário situar-se no intervalo de tolerância; caso a meta não seja cumprida, o Presidente do BC deveria justificar publicamente as razões do descumprimento, por meio de carta aberta ao Ministro da Fazenda; e, o BC deveria divulgar, a cada trimestre, um relatório de inflação, abordando o desempenho do regime, seus resultados e a avaliação prospectiva da inflação.

O CMN determinou que o Índice de Preços ao Consumidor Amplo (IPCA) seria o escolhido para balizar as metas de inflação, e o instrumento utilizado pelo BC para alcançar as metas foi definido pela Taxa Selic Overnight. Para além, o índice de inflação cheio foi o escolhido, em vez da seleção de um núcleo da inflação, sendo que este último isola o efeito de choques temporários sobre o nível geral de preços. No Brasil a escolha do núcleo da inflação foi rejeitada tendo em vista que se registra, na história recente do País, que expurgos de preços teriam sido utilizados para manipular 
os índices de inflação (MODENESI, 2005). Ressalta-se, ainda, o grau de flexibilidade do regime ao definir-se um intervalo de tolerância de dois pontos percentuais acima ou abaixo da meta central, que auxilia o BC a alcançar a meta de inflação no contexto de choques, internos e externos.

De maneira geral, foi apresentada, nesta seção, a abordagem teórica que sustenta o RMI, além da caracterização de sua sistemática. Ademais, de modo resumido, pôde-se observar o contorno institucional do RMI no Brasil, a partir da escolha do índice de preços, do horizonte temporal estipulado pelo BC para a convergência da meta, além do instrumento de política monetária utilizado. A seguir, busca-se analisar os pressupostos teóricos da abordagem pós-keynesiana, sua crítica ao RMI, além de sua alternativa de política monetária.

\section{A PERSPECTIVA PÓS-KEYNESIANA E A ALTERNATIVA DE POLÍTICA MONETÁRIA}

Os autores pós-keynesianos desenvolvem seus estudos tendo como base o funcionamento de economias monetárias de produção, como concebido por Keynes (1985 apud SICSÚ, 1997, p. 91), em que "a característica principal do conceito de economia monetária que o diferencia da hipótese da taxa natural de desemprego é a não neutralidade da moeda em quaisquer circunstâncias.” Pode-se conceber essa escola de pensamento como crítica ao NCM, e consequentemente ao RMI, visto que possuem pressupostos diferentes quanto ao funcionamento de economias capitalistas, sendo a principal oposição vista a partir da questão da neutralidade da moeda.

Enquanto os autores pertencentes ao NCM entendem que a moeda é neutra, exercendo apenas a função de facilitar as trocas, para os pós-keynesianos ela é um ativo, representando poder aquisitivo aos agentes no presente e no futuro, podendo, assim, reservar valor ao longo do tempo - principal função na explicação de como a moeda afeta variáveis reais em uma economia monetária. Como representa um ativo, como outro qualquer, mas com a peculiaridade de apresentar maior grau de liquidez, ${ }^{2}$

\footnotetext{
2 A moeda representa o ativo mais líquido da economia em razão das suas características peculiares, quais sejam, elasticidade de produção nula, elasticidade de substituição nula, além de ser unidade de conta da economia, sendo os salários e contratos denominados em moeda, o que a permite ter liquidez no decorrer do tempo.
} 
a moeda afeta as decisões dos agentes, que por meio dos motivos ${ }^{3}$ que têm para demandar moeda, podem apresentar maior ou menor grau de preferência pela liquidez, o que está diretamente ligado à determinação da taxa de juros.

Keynes (1985) sugere que todo agente possui uma avaliação subjetiva do que seria uma taxa normal de juros referente ao comportamento que espera dos ativos que transaciona. Nesse sentido, a taxa normal de juros “age como uma âncora para suas expectativas de movimentos futuros da taxa de juros de mercado e define se o agente será um urso ou um touro em face das taxas de juros correntes.” (CARVALHO, 1996, p. 52, grifo do autor). Assim, o significado da taxa de juros surge da combinação de características que, influenciadas pela preferência pela liquidez, fazem com que essa taxa seja mais ou menos sensível a mudanças na proporção que a quantidade de moeda apresenta frente a outras formas de riqueza/ativos. Isso indica que a taxa de juros equivale à recompensa por abrir mão de liquidez (moeda), já que ela "não é, em si, outra coisa senão o inverso da relação existente entre uma soma de dinheiro e o que se pode obter desistindo, por um período determinado, do poder de comando da moeda em troca de uma dívida.” (KEYNES, 1985, p. 122).

Logo, a importância da moeda em economias monetárias relaciona-se ao papel da taxa de juros, definida a partir da preferência pela liquidez dos agentes, ao representar uma variável relevante no cálculo do empresário ao tomar sua decisão de investir, baseada na comparação entre a taxa de juros e a eficiência marginal do capital - da remuneração de ativos não reprodutíveis e reprodutíveis de capital. Assim, “é a presença da moeda desempenhando o papel do ativo mais seguro em uma economia com incerteza knightiana que pode explicar a possibilidade de existência de diversos níveis de desemprego.” (SICSÚ, 1997, p. 92). Como a moeda não é neutra nem no curto, nem no longo período, para Keynes e os pós-keynesianos, a política monetária pode ser eficaz para alterar variáveis reais.

A política monetária pós-keynesiana visa à transformação da moeda-ativo em moeda meio de troca, agindo, assim, de modo a "induzir a viagem da moeda da circu-

\footnotetext{
${ }^{3}$ As razões para demandar moeda são, segundo Keynes (1985), motivadas para quatro fins: transação, precaução e especulação, sendo que, após a publicação da TG, em resposta à crítica feita por Ohlin, Keynes introduziu o quarto motivo, o financeiro (CARVALHO et al., 2007).
} 
lação financeira para a circulação industrial.”4 (CARVALHO et al., 2007, p. 95). Para tanto, recomenda-se ao BC aumentar o estoque monetário da circulação financeira, por meio das operações de mercado aberto, para, com isso, reduzir a taxa de juros de ativos não reprodutíveis e, assim, estimular as decisões privadas para a recomposição de portfólios mais ilíquidos, capazes de gerar emprego e renda.

Nesse quadro, concebe-se a política monetária como a manipulação do estoque de moeda com o fim de modificar a taxa de juros sobre os ativos líquidos, para, através de efeitos sobre os portfólios dos agentes privados, induzir movimentos de substituição das formas de riqueza, aumentando ou diminuindo a demanda por ativos reprodutíveis e, assim, aumentando ou diminuindo a renda gerada na produção de novos itens [...] O Banco Central age alterando seu próprio portfólio, valendo-se das obrigações que emite contra si mesmo, a moeda legal, para comprar, no mercado aberto, os ativos cuja disponibilidade objetiva criar. (CARVALHO, 1994, p. 47-48, grifo do autor).

Vê-se, assim, que a política monetária para essa escola de pensamento não apresenta o objetivo único de estabilidade de preços, tendo também a preocupação com as variáveis reais da economia. Nesse sentido, tanto a forma de operação da política monetária quanto os objetivos da AM sob a ótica pós-keynesiana adquirem novos contornos, "porque permite incluir entre os objetivos da política monetária os níveis de produto e emprego, bem como a busca de estabilizar um sistema econômico eminentemente instável.” (LIBÂNIO, 2004, p. 10).

Com isso, rejeita-se a noção de que apenas uma política monetária discricionária seria capaz de obter efeitos reais, como apontado pelo NCM. Para os autores pós-keynesianos, deve-se ter o anúncio prévio dos objetivos e instrumentos a serem utilizados pela AM, já que, como observado por Keynes (1985), a AM deve passar credibilidade ao público, já que se ele acredita que uma política monetária está sujeita

\footnotetext{
${ }^{4}$ No Treatise on Money, Keynes (1971) apresenta um modelo que relaciona os lados real e financeiro da economia, representados pelas chamadas circulação industrial e financeira. A circulação industrial corresponde à esfera responsável pela dinamização da produção corrente, contemplando as transações de bens e serviços na economia, em que se observam movimentações tanto de bens de capital quanto de bens de consumo. O volume de produtos e serviços, o nível de preços e a velocidade de circulação da moeda determinam a quantidade de moeda requerida nas transações dessa esfera. Por sua vez, a circulação financeira se refere às operações com ativos financeiros, envolvendo troca de títulos já existentes, compras de ações, transmissão de poupança corrente, entre outras. Na esfera financeira a moeda transforma-se em um ativo, como outro qualquer, com a especificidade de ter custo de manutenção nulo e liquidez plena.
} 
a muitas mudanças, ela pode falhar em seu objetivo, ao mesmo tempo que a mesma política pode ser aceita pelo público se este a considera compatível com seus interesses. Assim, “quanto mais claras as indicações dadas pelo governo, mais rápido e tranquilo seria o movimento naquela direção.” (CARVALHO, 1999, p. 276).

Defende-se, ainda, certo grau de arbítrio para a AM na condução da política monetária. A incerteza quanto ao futuro somada à necessidade de se adaptar à política econômica a situações específicas, exigem dos gestores de política alguma capacidade de mudança e adaptação, o que não é conseguido quando a AM age por meio de regras rigidamente definidas. Ademais, não seria conferida credibilidade a uma política que, destinada a certa conjuntura, mantém-se quando a situação já é diferente. “Assim sendo, seria desejável a manutenção de um certo grau de discrição, necessário para fazer frente a situações novas e imprevistas no futuro.” (LIBÂNIO, 2004, p. 12).

Para além, a consistência da política monetária depende também de sua coordenação com as demais políticas econômicas. Como apontado por Arestis e Sawyer (2003), fazem-se necessárias a coordenação e a consistência das políticas macroeconômicas, sobretudo fiscal e monetária, já que ambas apresentam efeitos sobre o nível de demanda agregada. Assim, é preciso que essas políticas persigam um objetivo comum, o que não seria possível no caso de um BC independente, como reivindicam os autores do NCM, focado apenas no objetivo de estabilizar o nível de preços. Logo, a questão da independência do BC não se coloca em discussão, uma vez que "a política monetária sempre tem efeitos reais a curto e longo prazo segundo a perspectiva pós-keynesiana e, portanto, não faz sentido lógico sugerir que o banco central cuide ‘apenas’ da estabilidade de preços.” (LIBÂNIO, 2004, p. 15).

Vê-se, pelo exposto, que os autores pós-keynesianos partem de pressupostos diferentes dos autores do NCM a respeito do funcionamento do sistema econômico, o que justifica a diferente concepção acerca do regime de política monetária a ser adotado. De modo geral, Saraiva e De Paula (2014) apresentam cinco elementos que dão sustentação ao RMI, passíveis de crítica por parte dos pós-keynesianos.

Em primeiro lugar, para os defensores do RMI a inflação é sempre um fenômeno meramente monetário, em que se observa a visão quantitativa da relação direta entre oferta de moeda e nível de preços. Arestis e Sawyer (2003) apontam que a inflação não tem como causa única elementos do lado da demanda, mas fatores relacionados à oferta, ao conflito distributivo e à capacidade produtiva insuficiente são importantes na explicação do aumento do nível de preços, o que não é captado pelo RMI. Além disso, tendo no RMI como único instrumento de política monetária o manejo da taxa de juros, agindo diretamente sobre a demanda agregada, e sendo a 
inflação causada também por choques de oferta, esse instrumento se mostra pouco eficaz para o controle dos preços.

Em segundo lugar, no NCM prega-se a existência de um trade-off de curto prazo entre inflação e desemprego, ao passo que, com a adoção da hipótese de expectativas racionais, associou-se a hipótese de uma taxa natural de desemprego, de modo que esse trade-off deixa de existir no longo prazo, o que significa neutralidade da moeda. Esse ponto é muito criticado pelos pós-keynesianos, uma vez que consideram como pressuposto o fato de a moeda afetar variáveis reais tanto no curto quanto no longo prazo. Ademais, consideram o futuro incerto e a tomada de decisões baseada em expectativas, não calculadas probabilisticamente, de modo que "a crítica às expectativas racionais não consiste em sugerir que a racionalidade é inatingível por seres humanos 'normais', mas em assumir que o conjunto de informações sobre as quais expectativas são formadas é sempre, inapelavelmente, incompleto.” (CARVALHO, 2009, p. 97).

O terceiro ponto diz respeito à crença no viés inflacionário da política monetária discricionária e à tese de independência do BC. Como apontado, Keynes (1985) já mencionava que a AM deveria ter como objetivos, além da manutenção do nível de preços, a preocupação com o nível de emprego da economia e o prezar pela estabilidade financeira. Nesse sentido, Davidson (2006 apud SARAIVA; DE PAULA, 2014) ressalta que, historicamente, a AM sempre teve como função primordial incentivar as instituições depositárias a concederem crédito, a taxas de juros baixas, e servir como emprestador de última instância, assegurando a ordem nos sistemas financeiros e garantindo a liquidez dos ativos, e não apenas servir como mantenedor da estabilidade dos preços. Para além, ao tratar da independência do BC,

Carvalho (1995) argumenta que a independência do BC é desejável, quando esta se propõe a isolar os objetivos da PM, as necessidades de acomodar o déficit da política fiscal, mas temerária quando os objetivos destas forem conflitantes e a PM for utilizada em uma direção contrária [...] Ademais, a crítica pós-keynesiana identifica que nas economias não existe um mecanismo de planejamento central (implícito) que coordene de forma eficiente as ações dos agentes econômicos, carecendo de instituições que assumam esta função, de modo a mitigar os riscos e incertezas inerentes a uma economia capitalista. (SARAIVA; DE PAULA, 2014, p. 8-9). 
Dessa forma, vê-se que a política monetária para os pós-keynesianos contempla mais de um objetivo, além de necessitar estar coordenada com o objetivo das demais políticas macroeconômicas. Nesse sentido, “quanto mais coordenados estiverem os instrumentos monetários entre si e esses, por sua vez, com os instrumentos fiscais, mais eficiente provavelmente será a política monetária.” (SICSÚ, 1997, p. 94).

A quarta proposição refere-se à validade da regra de Taylor por parte do RMI, funcionando como uma regra de política monetária do BC, que tem como instrumento a taxa de juros. A principal crítica pós-keynesiana a esse aspecto refere-se à desconsideração do efeito dos juros sobre outros canais de transmissão da política monetária, como os ativos financeiros e a taxa de câmbio, que traz problemas referentes à estabilidade financeira, como os efeitos da desregulamentação financeira e a presença de bolhas de ativos financeiros.

Por fim, a última consideração refere-se à adoção da inflação baixa e estável como âncora nominal do RMI. A crítica pós-keynesiana identifica que considerar a inflação como âncora nominal corresponde à manutenção do princípio de separação entre fatores reais e monetários da economia. Isso decorre diretamente da "hipótese de neutralidade da moeda no longo prazo e suas implicações ancoradas na tese de inconsistência temporal, representa que o trade-off de longo é inexistente e explorá-lo, no curto prazo, tem como consequência a elevação da inflação.” (SARAIVA; DE PAULA, 2014, p. 12).

Pelo exposto é possível perceber que para os pós-keynesianos o RMI não é um modelo de política monetária condizente com o funcionamento de economias monetárias, em que não há neutralidade da moeda. Dessa forma, a crítica de destaque, pelo foco deste artigo, consiste no fato de a inflação não ser causada apenas por fatores relacionados à demanda, sendo necessário entender quais os elementos causais da inflação. Ademais, tendo essa consideração em mente, faz-se necessário também compreender quais os instrumentos de política monetária devem ser utilizados pela AM, uma vez que apenas a taxa de juros não consegue influenciar todas as causas da inflação.

Tendo como foco a discussão acerca das diversas causas geradoras de inflação, Arestis e Sawyer (2013) ressaltam que a equação representativa da Curva de Phillips, no RMI, denota que a variação de preços é função do nível de demanda e da taxa de inflação esperada, em que o papel das expectativas representaria as variações dos demais preços da economia. Entretanto, essa equação omite uma interação entre preços diferentes, como, por exemplo, na relação entre salários e preços, além da ausência de uma relação entre o nível de preços e o nível de custos da economia. Assim, “a versão da Curva de Phillips [...] é uma forma (muito) reduzida que não conside- 
ra explicitamente os salários, custos de material e preços importados.” (ARESTIS; SAWYER, 2003, p. 4, tradução nossa).

Nesse sentido, a explicação das causas da inflação deve contemplar também aspectos do lado da oferta, como, por exemplo, nível de custos, margens de lucro, conflito distributivo e estrutura de mercado. Desse modo, “em geral, a inflação na teoria pós-keynesiana se relaciona à elevação dos custos de produção [...] e ao conflito entre diversos grupos pela distribuição da renda nacional” (LIBÂNIO, 2004, p. 17), não sendo, assim, concebível que a política monetária detenha o objetivo único de estabilização do nível de preços via taxa de juros, visto que essa taxa ataca os sintomas e não as causas da inflação (SICSÚ, 2003).

Para os pós-keynesianos existem vários tipos de inflação, sendo que para cada tipo se deve utilizar um instrumento anti-inflacionário específico, “então, o método pós-keynesiano é o de busca das causas (identificação das pressões de origem) para construir uma agenda-positiva de controle da inflação.” (SICSÚ, 2003, p. 7, grifo do autor). Nesse sentido, Sicsú (2003) apresenta os tipos existentes de inflação, com suas respectivas causas e medidas a serem tomadas, e reforça que a relação entre causa e receituário não é direta, podendo existir mais de uma política para determinado tipo de inflação, e ainda políticas que gerem efeitos em outras variáveis econômicas. Ademais, as causas apontadas para a explicação da inflação podem ter maior ou menor impacto sobre esta, a depender do hiato do emprego, do grau de abertura e de monopólio da economia.

O primeiro tipo de inflação elencado pelo autor corresponde à de salários, resultante das negociações entre trabalhadores e empresários, de modo que um aumento dos salários nominais, tudo o mais constante, causará inflação. Geralmente esse tipo de inflação é mais eminente quando o hiato do emprego é menor, já que se torna mais fácil para os trabalhadores obterem ganhos salariais, e, com isso, os empresários repassam essa elevação de seus custos para os preços. Entretanto, um aumento salarial não causará inflação se for compensado por ganhos de produtividade, sendo que esta depende fortemente de políticas de desenvolvimento tecnológico e de qualificação profissional.

O segundo tipo de inflação refere-se ao grau de monopólio do mercado, sendo denominada inflação de lucros. Ela é observada quando os empresários percebem que a demanda em seus mercados possui elasticidade favorável ao aumento de suas margens de lucro, e, dessa forma, aumentam o preço de seus produtos. Sicsú (2003) aponta que há autores que creem que essas margens são aumentadas na fase de crescimento econômico, ao passo que outros acreditam no oposto, mas o essencial é ter em 
mente que "o potencial da inflação de lucros depende diretamente do grau de monopólio da economia.” (SICSÚ, 2003, p. 9).

A inflação de retornos decrescentes assume importância em momentos em que o hiato do emprego já é baixo e ainda sofre alguma redução, situação próxima ao nível de pleno emprego. Isto ocorre porque quando o hiato do emprego é muito baixo, o capital torna-se mais eficiente que o trabalho, e, assim, são contratados trabalhadores menos qualificados que utilizam o capital de maneira menos eficiente, gerando menos produtividade, sendo que as firmas não possuem métodos para se precaverem de escassez de mão de obra qualificada.

O quarto tipo denomina-se inflação importada e ocorre quando a trajetória de preços no exterior influencia os preços domésticos, sendo dependente da variação do nível de preços internacional e/ou da taxa de câmbio. Pode-se afirmar que quanto maior o grau de abertura da economia, maior tende a ser a inflação importada potencial, já que mais produtos podem ser adquiridos do exterior em relação ao total de produtos adquiridos por residentes. Nesse sentido, caso haja aumento dos preços dos produtos importados, com a taxa de câmbio constante, há aumento dos preços domésticos; de maneira similar, caso os preços no exterior se mantenham, mas a taxa de câmbio sofra uma desvalorização, há inflação. O hiato do emprego e o grau de monopólio da economia também podem explicar o potencial da inflação importada, já que uma elevação de preço dos produtos importados representa um custo adicional para as empresas domésticas que utilizam ou comercializam tais produtos, sendo esses custos "mais facilmente repassados aos preços quando o hiato do emprego é baixo ou quando o grau de monopólio (do setor atingido pelo problema externo) é elevado.” (SICSÚ, 2003, p. 11).

Há ainda os choques inflacionários, considerados os choques domésticos capazes de provocar elevação dos custos, que podem ser exemplificados por choques de safras agrícolas. De maneira similar às análises anteriores, esse tipo de inflação é mais fácil de ocorrer quando o hiato do emprego é menor e o grau de monopólio do setor é elevado. Outra categoria seria a inflação de impostos, que se refere ao fato de que uma alteração nas alíquotas de impostos tende a elevar o nível de preços e, como os demais tipos, essa inflação é mais facilmente observada quando o hiato do emprego é baixo e o grau de monopólio alto.

Por fim, concebe-se a inflação de demanda, que ocorre quando o hiato do emprego deixa de ser positivo, ou seja, os aumentos dos componentes da demanda como investimento e gastos do governo provocam inflação. "Sendo assim, a inflação 
de demanda potencial tende a se elevar quando o hiato do emprego é zero.” (SICSÚ, 2003, p. 12).

Ao apresentar as medidas anti-inflacionárias para esses tipos de inflação, Sicsú (2003) apresenta a tax-based on incomes policy (TIP), desenvolvida por Weintraub e Wallich em 1978 e incorporada pelos pós-keynesianos. Para a TIP, aumentos salariais ou de lucros acima das possibilidades proporcionadas pelos ganhos de produtividade são prejudiciais à sociedade. Assim, sugere-se o pagamento de impostos que incidam sobre as grandes empresas que concedem aumentos salariais ou suas margens de lucro acima dos aumentos de produtividade. Assim, a TIP atuaria no combate tanto da inflação de salários quando da inflação de lucros.

Por sua vez, a inflação de rendimentos decrescentes também gera um custo a toda a sociedade, em uma situação de crescimento em que não haja programas permanentes de treinamento e qualificação dos trabalhadores e desenvolvimento tecnológico. Assim, "no curto prazo, essa inflação não tem como ser evitada. Mas, no longo prazo, deve ser eliminada, se políticas adequadas estão sendo implementadas.” (SICSÚ, 2003, p. 15).

Quanto à inflação de impostos, esta deve ser evitada pelo próprio Governo, responsável pela estabilidade do valor da moeda, reduzindo os impostos, se possível, de empresas que tiveram seus custos aumentados, para que mantenham suas margens de lucros e não haja repasse aos preços. Já a inflação importada pode ser combatida via políticas cambiais, tributárias e monetárias, sendo todas complementares. Entretanto, para uma posição mais favorável no longo prazo, os pós-keynesianos sugerem a adoção de políticas industriais de incentivo à exportação e à produção nacional de produtos importados, tornando a economia menos dependente do exterior.

Os choques inflacionários ocorrem de maneira repentina, como no aumento da demanda ou na redução da oferta de algum produto. "Este tipo de inflação pode ser facilmente evitada se existe alguma instituição que não está orientada pelo auto-interesse, e que manterá um estoque de proteção (buffer stock) para prevenir variações imprevistas que induzem amplas variações do preço spot.” (DAVIDSON, 1994 apud SICSÚ, 2003, p. 16). Dessa forma, seria possível controlar a oferta e a demanda desses produtos de modo a evitar as variações repentinas de seus preços.

Sicsú (2003) ressalta, ainda, a questão dos preços administrados, muito comum no Brasil, que corresponde aos preços reajustados automaticamente segundo regras contratuais de indexação ou regulados em negociações com o setor público. Para os pós-keynesianos, todos os contratos desse gênero devem ser eliminados e novos 
devem ser impedidos, já que na prática agem no sentido de estimular e realimentar a inflação.

Por fim, no que se refere à inflação de demanda, há a sugestão de que as medidas de expansão econômica sejam relaxadas antes que o pleno emprego seja atingido, mantendo a economia em um quase boom, como apontado por Keynes (1985). Caso ocorra esse tipo de inflação, políticas contracionistas devem ser utilizadas, como, por exemplo, redução dos gastos governamentais, além da utilização da taxa de juros, visto que contribuem para o esfriamento da demanda.

Vê-se, assim, que para os pós-keynesianos a inflação é explicada por múltiplos fatores, não apenas pelos componentes da demanda agregada, como pressupõe o RMI. Dessa maneira, busca-se, por meio do referencial teórico analisado, entender de maneira empírica a dinâmica de preços no Brasil, pós-RMI, de modo a se auferir quais as causas relevantes da inflação no País, além de se contemplar um possível regime de política monetária condizente com o funcionamento de uma economia monetária.

\section{METODOLOGIA, VARIÁVEIS E RESULTADOS}

O objetivo com este trabalho consistiu em investigar empiricamente quais são as variáveis explicativas das causas da inflação brasileira no período pós-Regime de Metas de Inflação, tendo em vista o referencial teórico pós-keynesiano. Para tanto, será utilizada a metodologia econométrica de vetores autorregressivos (VARs).

Os VARs são uma extensão de um modelo univariado autorregressivo para séries temporais multivariadas. O modelo é constituído por um sistema de equações lineares dinâmicas, em que cada variável é representada como função de um erro serialmente não correlacionado e todas as variáveis pertencentes ao sistema possuem o mesmo número de defasagens. As defasagens determinam a ordem do modelo, de modo que VAR (1), por exemplo, representa um modelo vetor autorregressivo com uma defasagem (BUENO, 2008).

Essa metodologia trata todas as variáveis analisadas como endógenas, formando um sistema de equações estimadas por Mínimos Quadrados Ordinários (MQOs). Assim, o VAR se mostra útil para a análise das interações propostas neste trabalho, já que possibilita observar as relações dinâmicas entre as variáveis endógenas consideradas, sem a necessidade de se definir previamente a causalidade entre elas. 
O modelo aqui proposto compreende as seguintes variáveis ${ }^{5}$ : taxa de inflação (IPCA), calculada pelo IBGE por meio do Índice de Preços ao Consumidor Amplo (IPCA), em sua variação mensal; inflação defasada (IPCADEF), contemplando o peso inercial da inflação; expectativa de inflação (EXPECIPCA), por meio da expectativa média do IPCA para os próximos 12 meses, contemplando os efeitos da expectativa sobre a inflação futura na explicação da inflação presente; hiato do produto (HIATOPRO), representando os choques pelo lado da demanda à inflação, sendo considerado o índice IBC-BR dessazonalizado do BC do Brasil como proxy do índice de atividade econômica do País, obtendo o hiato mediante a diferença entre a série e sua tendência, por intermédio do filtro Hodrick-Prescott (HP); taxa SELIC (SELIC) que mostra a variação da taxa de juros acumulada no mês em termos anualizados, representando uma das fontes de pressões de custo sobre a inflação ${ }^{6}$; e, por fim, para captar os efeitos da inflação importada sobre a inflação corrente - sendo mais um componente dos choques de custos à inflação -, utiliza-se o índice de commodities-Brasil (COMMOD) e a taxa de câmbio real efetiva (TXCR).

Dessa maneira, o modelo proposto tem como variável relevante a explicação da taxa de inflação, o IPCA. Como em uma tentativa de se esboçar uma Curva de Phillips alternativa à original, buscam-se como variáveis explicativas aquelas que se relacionam com todos os condicionantes da inflação apontados tanto pelo lado da demanda, representado pelo hiato do produto, quanto pelos destacados pelo referencial teórico aqui abordado como relevantes na explicação da inflação pelo lado da oferta, quais sejam, a variação da taxa de juros e os componentes que captam a inflação importada - índice de commodities e taxa de câmbio real efetiva. A ideia original do trabalho consistia em captar tais efeitos a partir do período de implementação do RMI no Brasil, realizado em 1999. Entretanto, em razão da disponibilidade uniforme dos dados selecionados, a periodicidade analisada foi mensal, contemplando de 2003/01 a 2016/01, tendo, portanto 157 observações.

\footnotetext{
${ }^{5}$ As variáveis utilizadas neste trabalho foram retiradas dos bancos de dados IPEA-DATA (INSTITUTO DE PESQUISA ECONÔMICA APLICADA, 2016) e Sistema Gerenciador de Dados do BC do Brasil (BANCO CENTRAL DO BRASIL, 2016).

${ }^{6}$ Conforme destacam Summa e Macrini (2014), mudanças na taxa de juros nominal podem ser analisadas no escopo das pressões de custo sobre a inflação, uma vez que agem tanto sobre os custos financeiros para empresas endividadas, por exemplo, quanto sobre o custo de oportunidade do capital, pelo fato de a margem nominal de lucros seguir a taxa nominal de juros e, assim, gerar pressões inflacionárias.
} 
Tabela 1 - Estatísticas Descritivas

\begin{tabular}{lrrrrr}
\hline & \multicolumn{1}{c}{ Média } & \multicolumn{1}{c}{ Mediana } & \multicolumn{1}{c}{ Máximo } & \multicolumn{1}{c}{ Mínimo } & Desvio padrão \\
\hline IPCA & 0.516154 & 0.480000 & 2.250000 & -0.210000 & 0.318368 \\
HIATOPRO & 208.4192 & 143.5501 & 530.5653 & 72.64338 & 132.8980 \\
IPCADEF & 0.511290 & 0.480000 & 2.250000 & -0.210000 & 0.313532 \\
COMMOD & 117.0540 & 108.2300 & 189.3400 & 86.67000 & 23.06671 \\
TXCR & 98.39325 & 94.0000 & 160.1900 & 71.76000 & 20.28211 \\
EXPECIPCA & 5.459487 & 5.52000 & 11.72000 & 3.400000 & 1.245109 \\
SELIC & 13.14580 & 11.92000 & 26.32000 & 7.110000 & 4.409227 \\
\hline FOC
\end{tabular}

Fonte: adaptada da Saída do Eviews 8.0.

A Tabela 1 apresenta as estatísticas descritivas das variáveis utilizadas na modelagem VAR. Observa-se que todas as variáveis apresentam fortes oscilações no período considerado, apontando grande discrepância em relação aos seus valores máximo e mínimo, indicando a instabilidade inerente a essas variáveis macroeconômicas. Destaca-se, sobretudo, a grande variação observada na série HIATOPRO, indicando valor máximo de 530.5653 e mínimo de 72.64338, sendo a série que representa os choques de demanda na explicação da inflação; e, pelo lado da oferta, as grandes oscilações observadas nas séries que captam os choques de inflação importada, tendo a série COMMOD apresentado máximo de 189.3400 e mínimo de 86.67000, ao passo que a série que retrata a variação cambial apresentou máximo de 160.1900 e mínimo de 71.76000 .

A Tabela 2 apresenta os resultados dos testes de estacionariedade ${ }^{7}$ das séries do modelo VAR. Foram realizados os testes Argumented Dickey-Fuller (ADF), Phillips-Perron (PP), Kwiatkowski-Phillips-Schmidt-Shin (KPSS) e o Dickey-Fuller GLS (DF-GLS). Vale ressaltar que a hipótese nula dos testes $A D F, P P$ e $D F-G L S$ é de que a série possui raiz unitária, sendo, assim, não estacionária. Já o teste KPSS tem como hipótese nula a série não possuir raiz unitária, e, dessa forma, ser estacionária.

Como pôde ser observado, todas as séries apresentaram raiz unitária em nível. Destaca-se o caso das séries EXPECIPCA, IPCA e IPCADEF que não apresentaram raiz unitária em nível pelos testes $A D F$ e $P P$, mas, que, pelos testes KPSS e $D F-G L S$, que apresentam relativamente maior confiança, foram consideradas não estacionárias em nível. Dessa forma, foram utilizadas as primeiras diferenças de todas as séries, sendo, assim, estacionárias em primeira diferença e recebendo a seguinte de-

\footnotetext{
${ }^{7}$ Destaca-se que para utilizar a metodologia VAR todas as variáveis precisam ser estacionárias, portanto, não possuir raiz unitária.
} 
nominação: DIPCA, DHIATOPRO, DIPCADEF, DCOMMOD, DTXCR, DEXPEC, DSELIC.

Tabela 2 - Testes de Estacionariedade

\begin{tabular}{|c|c|c|c|c|}
\hline & ADF & PP & KPSS & DF - GLS \\
\hline COMMOD & $\mathrm{a}$ & $\mathrm{a}$ & $\mathrm{a}$ & c \\
\hline T-stat & -1.366911 & -1.552861 & 0.325757 & -1.726179 \\
\hline Prob & 0.8668 & 0.8069 & - & - \\
\hline EXPECIPCA & a & $\mathrm{a}$ & $\mathrm{a}$ & c \\
\hline t-stat & $-5.314958(* * *)$ & $-5.858966(* * *)$ & 0.333847 & -0.526440 \\
\hline Prob & 0.0001 & 0.0000 & - & - \\
\hline HIATOPRO & $\mathrm{a}$ & $\mathrm{a}$ & $\mathrm{a}$ & c \\
\hline t-stat & -2.606732 & -1.528355 & 0.244042 & -1.713887 \\
\hline Prob & 0.2780 & 0.8158 & - & - \\
\hline IPCA & $\mathrm{a}$ & $\mathrm{a}$ & $\mathrm{a}$ & c \\
\hline t-stat & $-7.206333(* * *)$ & $-7.206333(* * *)$ & 0.226712 & -1.859075 \\
\hline Prob & 0.0000 & 0.0000 & - & - \\
\hline IPCADEF & a & $\mathrm{a}$ & $\mathrm{a}$ & c \\
\hline t-stat & $-7.478564(* * *)$ & $-7.488297(* * *)$ & 0.213699 & -1.959265 \\
\hline Prob & 0.0000 & 0.0000 & - & - \\
\hline SELIC & a & $\mathrm{a}$ & $\mathrm{a}$ & c \\
\hline t-stat & $-4.016138(*)$ & -1.857823 & 0.267946 & -1.293421 \\
\hline Prob & 0.0101 & 0.6715 & - & - \\
\hline TXCR & a & $\mathrm{a}$ & a & c \\
\hline t-stat & -1.860796 & -0.946863 & 0.347311 & -0.751226 \\
\hline Prob & 0.6700 & 0.9470 & - & - \\
\hline
\end{tabular}

Fonte: adaptada da Saída do Eviews 8.0.

Nota 1: Presença de intercepto e tendência (a); presença de constante (b); sem constante e tendência (c). Nota 2: Estacionário a 1\% (***); Estacionária a 5\% (**); Estacionária a 10\% (*).

Após a realização dos testes de estacionariedade, partiu-se para a especificação e a escolha da defasagem do modelo VAR, conforme pode ser observado pela Tabela 3. De acordo com os valores apresentados pelo procedimento LAG CRITERIA, foi escolhido um modelo com três defasagens, sendo representado por VAR (3), já que os menores valores apresentados pelos critérios de informação da Akaike e Hannan-Quinn apontam para tal especificação.

Na sequência, foi estimado o modelo VAR (3) e testada sua estabilidade, por meio da análise $A R$ ROOTS, representada pelo Gráfico 1. Como se nota, todas as representações em forma de ' $x$ ' se encontram dentro da demarcação do círculo, que representa a delimitação de raiz unitária, logo, o modelo VAR (3) é considerado estável. 
Tabela 3 - Seleção do Modelo VAR

\begin{tabular}{|c|c|c|c|c|c|c|}
\hline Variáveis Enc & enas: DIP & DIPCADE & $\begin{array}{l}\text { EXPECIP } \\
\text { DTXCR }\end{array}$ & DHIATO & DCOMM & DSELIC \\
\hline & & Var & el Exógena: & & & \\
\hline $\begin{array}{l}\text { Defasagem } \\
\text { LogL }\end{array}$ & & LR & FPE & AIC & SC & $\mathbf{H} \mid \mathbf{Q}$ \\
\hline 0 & -1441.847 & NA & 5.809182 & 21.62458 & 21.77596 & 21.68609 \\
\hline 1 & -974.2717 & 879.3200 & 0.011255 & 15.37719 & 16.58823 & 15.86932 \\
\hline 2 & -670.4606 & 539.6049 & 0.000252 & 11.57404 & $13.84473^{*}$ & 12.49678 \\
\hline 3 & -579.1782 & 152.5915 & $0.000136 *$ & 10.94296* & 14.27331 & $12.29631 *$ \\
\hline 4 & -545.7793 & 52.34145 & 0.000177 & 11.17581 & 15.56582 & 12.95977 \\
\hline 5 & -482.5508 & $92.48349 *$ & 0.000150 & 10.96345 & 16.41311 & 13.17801 \\
\hline 6 & -446.3143 & 49.21679 & 0.000194 & 11.15394 & 17.66327 & 13.79912 \\
\hline
\end{tabular}

Fonte: adaptada da Saída do Eviews 8.0.

Nota: * indica a ordem da defasagem pelo critério de seleção.

AIC: Critério de Informação de Akaike.

SC: Critério de Informação de Schwarz.

HQ: Critério de Informação de Hannan-Quinn.

* indica a ordem da defasagem pelo critério de seleção.

AIC: Critério de Informação de Akaike.

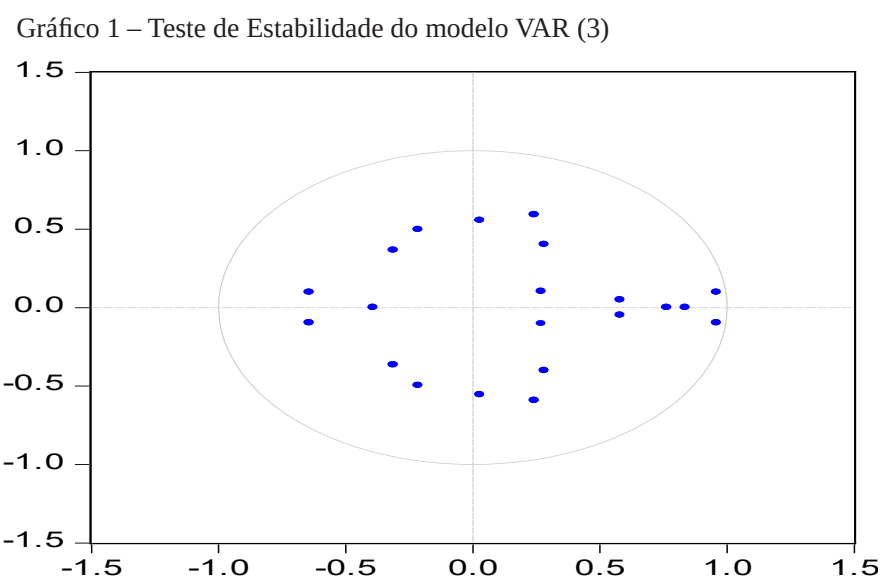

Fonte: adaptado da Saída do Eviews 8.0.

Para a garantir a confiabilidade do modelo, é preciso também que se observe a ausência de autocorrelação. A autocorrelação é entendida como a correlação entre as variáveis da série e pode ocorrer, entre outros motivos, em decorrência da inércia, viés de especificação do modelo, defasagens, transformação dos dados, além da ausência de estacionariedade. Na presença de autocorrelação há viés nos estimadores, 
e subestima-se a variância residual, assim como o erro padrão, o que leva também a problemas na interpretação dos testes de significância t e F (GUJARATI, 2006).

Um dos testes mais utilizados para se detectar a presença de autocorrelação é o de Breusch-Godfrey (Serial Correlation LM test), sendo que, considerando o nível de significância de $5 \%$, se o p-valor for maior que 0,05 não se rejeita a hipótese nula de inexistência de autocorrelação, enquanto que se o p-valor for menor que 0,05 , rejeita-se a hipótese nula e, portanto, há autocorrelação. Como pode ser observado na Tabela 4, por meio dos resultados do teste LM, o modelo VAR com três defasagens não sofre do problema de autocorrelção, já que o p-valor é maior que 0,05:

Tabela 4 - Teste de autocorrelação (teste LM) - modelo VAR (3)

H0: não há correlação serial na defasagem de ordem $h$

\begin{tabular}{cccc}
\hline Defasagem & \multicolumn{2}{c}{ LM-Stat } & Prob \\
\hline 1 & 68.53791 & 0.0540 \\
2 & 72.18863 & 0.0572 \\
3 & 53.45222 & 0.3072 \\
4 & 62.62675 & 0.0914 \\
5 & 68.29462 & 0.0355 \\
6 & 52.68763 & 0.3334 \\
7 & 57.51885 & 0.1890 \\
8 & 63.64968 & 0.0779 \\
9 & 35.79141 & 0.9205 \\
10 & 37.56307 & 0.8832 \\
11 & 79.50694 & 0.0038 \\
12 & 24.26929 & 0.9988 \\
\hline
\end{tabular}

Fonte: adapdada da Saída do Eviews 8.0.

*Probabilidades a partir de Qui-quadrados com 16 defasagens.

Os resultados do modelo VAR podem ser analisados por meio da estimação da Função de Resposta aos Impulsos, em que se verifica o sentido dos efeitos de cada variável (impulso) sobre as demais (resposta). Além disso, há a análise mediante a decomposição da variância, em que se procura a porcentagem da variância de erro de previsão decorrente de cada variável endógena.

Inicialmente, ao se analisar a Função de Resposta aos Impulsos, procurou-se destacar as respostas da série DIPCA - taxa de inflação -, aos impulsos das demais séries elencadas no modelo VAR. O intuito é entender o sentido das respostas da in- 
flação aos choques de demanda e oferta da economia, além de captar a relevância dos efeitos dos choques de expectativas da inflação e da inflação defasada.

Por intermédio da análise do Gráfico 2, pode-se constatar que a inflação responde de maneira negativa aos choques do hiato do produto. Essa relação se coloca pelo fato de que se aumentando o hiato do produto, ou seja, a diferença observada entre a atividade econômica e sua tendência de longo prazo, a inflação tende a diminuir, ao passo que, quando a diferença entre a atividade econômica observada e sua tendência de longo prazo diminui, a economia se encontra próximo de seu nível ótimo; assim, mais aquecida, a inflação responde de maneira positiva.

Em relação aos choques da inflação defasada e da expectativa de inflação, pode-se perceber que ambos os choques provocam respostas no sentido positivo por parte da inflação no período considerado, ou seja, um choque positivo de inflação passada e/ou um choque positivo na expectativa dos agentes quanto à dinâmica futura do nível de preços tende a fazer com que a inflação presente responda de maneira positiva.

Gráfico 2 - Função de Resposta aos Impulsos
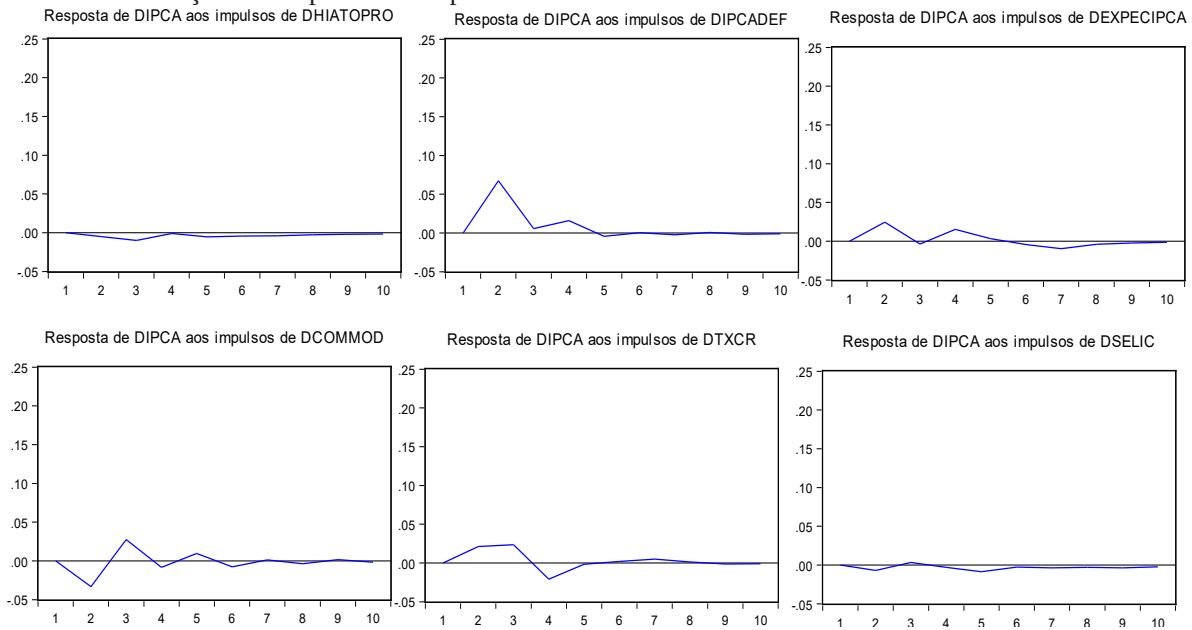

Resposta de DIPCA aos impulsos de DSELIC

Fonte: adaptado da Saída do Eviews 8.0.

De maneira semelhante, pode-se analisar o choque da inflação importada sobre a dinâmica da inflação presente, ao constatar-se o sentido positivo pelo qual a série DIPCA responde aos choques do índice de commodities e da taxa de câmbio real efetiva, na maior parte do período, indicando que uma subida em ambas essas séries faz com que a inflação responda de maneira positiva. Por fim, quanto ao outro componente da inflação de custos, representado pela taxa de juros, pouco se pode concluir a 
respeito de seu peso na explicação da inflação a partir da análise do impulso-resposta, visto que apenas em parte do período se constatou o sentido negativo da resposta da inflação, indicando que um aumento da SELIC provoca retração da inflação observada, o que condiz com o referencial teórico analisado neste trabalho.

A seguir, parte-se para a análise da decomposição da variância, que corresponde à porcentagem da variância de erro de previsão decorrente de cada variável endógena do modelo. Assim, diferentemente da análise da resposta aos impulsos, na decomposição da variância o sentido dos efeitos não é o mais importante, mas o valor relativo dos efeitos de cada variável sobre o erro de previsão das demais variáveis.

Na Tabela 5 é expressa a análise da decomposição da variância da taxa de inflação em relação às demais variáveis. Como esperado, vê-se que a maioria da variância de previsão de uma variável é explicada pelos choques à própria variável, sendo a taxa de inflação explicada totalmente por si mesma no primeiro período, visto que, no final do período, ela própria se explica em 84,03\% aproximadamente.

Tabela 5 - Decomposição da Variância - DIPCA

\begin{tabular}{rccccccc}
\hline \hline Período & DIPCA & $\begin{array}{c}\text { DHIA- } \\
\text { TOPRO }\end{array}$ & $\begin{array}{c}\text { DIPCA- } \\
\text { DEF }\end{array}$ & $\begin{array}{c}\text { DCOM- } \\
\text { MOD }\end{array}$ & DTXCR & $\begin{array}{c}\text { DEXPE- } \\
\text { CIPCA }\end{array}$ & DSELIC \\
\hline 1 & 100.0000 & 0.000000 & 0.000000 & 0.000000 & 0.000000 & 0.000000 & 0.000000 \\
5 & 84.49658 & 0.253044 & 7.955765 & 3.297749 & 2.361541 & 1.401507 & 0.233813 \\
10 & 84.03595 & 0.329137 & 7.912339 & 3.401489 & 2.395329 & 1.611598 & 0.314161 \\
\hline
\end{tabular}

Fonte: adaptado da Saída do Eviews 8.0.

Vale destacar nessa análise que o componente de inércia da inflação, representado pela série DIPCADEF, compreende aproximadamente 7,91\% da variância da DIPCA, além de que a série representativa das expectativas dos agentes em relação à inflação futura explica em 1,61\% a variância da inflação. Vê-se que tais componentes representam um peso significativo na explicação da inflação brasileira no período considerado, sobretudo em razão do fato de que a variável DHIATOPRO, que representa os choques de demanda - principal fator causal da inflação para o NCM -, explica apenas 0,32\% da variância da taxa de inflação.

Por fim, dando robustez aos pressupostos pós-keynesianos de que a inflação consiste em um fenômeno multicausado, os fatores do lado da oferta da economia possuem significância na explicação da inflação observada. A série DCOMMOD explica em 3,4\% a variância da inflação, enquanto a taxa de câmbio real efetiva e a taxa de juros explicam em, respectivamente, 2,39\% e 0,31\%. Assim, observa-se que os componentes do lado da oferta da economia explicam de maneira conjunta aproxi- 
madamente 6,5\% da variância da inflação, possuindo um peso muito maior que os choques de demanda.

\section{CONSIDERAÇÕES FINAIS}

Neste trabalho buscou-se analisar a dinâmica de preços no Brasil no período de 2003 a 2016. No País é utilizado o RMI, como regime monetário, que tem como sustentação os pressupostos do NCM, em que se observam fatores do lado da demanda como causadores da inflação e, portanto, justifica-se o uso da taxa de juros como principal instrumento de política monetária. Seguindo uma perspectiva pós-keynesiana, muitas críticas podem ser levantadas quanto ao modo de funcionamento e à efetividade do RMI. Neste trabalho enfatizou-se o fato de que a inflação se configura como um fenômeno multicausado, sendo o nível de preços influenciado por fatores tanto do lado da demanda quanto do lado da oferta da economia.

Dessa forma, com o propósito de se analisar empiricamente a dinâmica de preços no Brasil no período em questão, no trabalho utilizou-se a metodologia VAR, em uma tentativa de esboçar uma Curva de Phillips alternativa à original. Assim, no modelo as variáveis explicativas da inflação são, além das expectativas quanto à inflação futura, a inflação defasada e o nível de atividade econômica - representado pelo hiato do produto -, também fatores do lado da oferta, representados pela variação da taxa de juros básica da economia, índice de commodities - que capta o peso dos preços dos produtos tradables -, além da variação da taxa de câmbio real efetiva, tão relevante na explicação da inflação de uma economia emergente como a brasileira.

Os resultados do modelo VAR podem ser analisados por meio do impulso-resposta e da decomposição da variância. No primeiro caso, analisa-se a resposta da série que mede a inflação brasileira no período de 2003 a 2016 aos impulsos das demais séries do modelo. Pôde-se verificar, como esperado, que o nível de preços respondeu de maneira negativa aos impulsos do hiato do produto (principal componente representante do lado da demanda da economia), indicando, por exemplo, que em momentos em que a economia se encontra mais aquecida e, portanto, apresenta o hiato do produto menor, há aumentos da inflação. No que se refere à inflação defasada e às expectativas quanto à inflação futura, observou-se que ambas provocam uma resposta de sentido positivo no nível de preços, uma vez que a inércia inflacionária, assim como expectativas de que os preços aumentarão, contribuem para a elevação do nível de preços. Em relação aos aspectos que representam o lado da oferta da economia, observam-se respostas positivas da inflação aos impulsos do índice de commodities e 
da taxa de câmbio real efetiva, na maior parte do período, indicando que uma subida em ambas essas séries faz com que a inflação responda de maneira positiva. Já quanto à série que representa os efeitos dos juros sobre a inflação, observa-se uma resposta negativa, na maior parte do período, indicando que os aumentos dos juros levam à redução da inflação.

A segunda maneira pela qual o modelo VAR permite que seus resultados sejam analisados é por meio da decomposição da variância e, no caso específico deste trabalho, a contribuição dessa análise se destaca. Diferentemente da análise da resposta aos impulsos, na decomposição da variância o sentido dos efeitos não é o mais importante, mas sim o valor relativo dos efeitos de cada variável sobre o erro de previsão das demais variáveis. Assim, pôde-se observar que a inflação brasileira no período é explicada em 7,91\% pela inflação defasada; 1,61\% pela expectativa inflacionária; apenas $0,32 \%$ pelo hiato do produto e, em 6,5\% pelos fatores do lado da oferta da economia (3,40\% índice de commodities; 2,39\% taxa de câmbio e 0,31\% taxa de juros). Nota-se com esses resultados, que a dinâmica de preços no Brasil é explicada tanto por fatores do lado da demanda quanto por fatores do lado da oferta, além de que a inércia inflacionária e a incerteza quanto ao comportamento da economia representam um grande peso sobre essa variável.

Assim, essa análise empírica mostra que a realidade inflacionária brasileira se aproxima muito mais ao arcabouço desenvolvido pelos pós-keynesianos do que pelos pressupostos do RMI. Para além, vê-se, claramente, que a utilização por si só da taxa de juros como instrumento de política monetária por parte da Autoridade Monetária não é suficiente, uma vez que esta taxa afeta, direta e sobretudo o lado da demanda da economia, sendo que os componentes da oferta devem receber atenção especial no controle de preços por parte do Banco Central. Assim como ressaltado na seção 3, medidas relacionadas à política industrial e cambial são de suma importância para que o peso da inflação importada represente problema menor no combate da inflação. Além disso, medidas que busquem aplacar a inércia inflacionária devem ser adotadas, sobretudo, as condizentes com o problema da indexação, tão presente no país. E, de suma importância também, destaca-se o papel de segurança que o Banco Central deve passar aos agentes, visto que a expectativa dos agentes frente ao comportamento da economia, mas, sobretudo, frente à dinâmica dos preços no futuro, dita, sobremaneira, o patamar que estes preços irão atingir no presente. 


\section{REFERÊNCIAS}

ARESTIS, P.; SAWYER, M. Moving from Inflation Targeting to prices and incomes policy. Panoeconomicus, v. 1, i. 1, p. 1-17, 2013.

ARESTIS, P.; SAWYER, M. The nature and role of monetary policywhen money is endogenous. The Levy Economics Institute of Bard College Working Paper, n. 374, mar. 2003.

BANCO CENTRAL DO BRASIL. Economia e Finanças. Séries Temporais. Disponível em: <http://www4.bcb.gov.br/?SERIESTEMP>. Acesso em: jun. 2016.

BRASIL. Decreto-Lei n. 3.088, de 21 de junho de 1999. Estabelece a sistemática de “metas para a inflação” como diretriz para fixação do regime de política monetária e dá outras providências. Diário Oficial da União, Brasília, DF, 22 jun. 1999.

BUENO, R. de L. da. S. Econometria de Séries Temporais. São Paulo: Cengage Learning Edições Ltda., 2008.

CARRARA, A. F.; CORREA, A. L. O Regime de Metas de Inflação no Brasil: uma análise empírica do IPCA. Revista de Economia Contemporânea, Rio de Janeiro, v. 16, n. 3, set./dez. 2012.

CARVALHO, F. C. et al. Economia Monetária e Financeira: teoria e política. Rio de Janeiro: Campus, 2007.

CARVALHO, F. C. O retorno de Keynes. Novos Estudos - CEBRAP, São Paulo, n. 83, 2009.

CARVALHO, F. C. Políticas econômicas para economias monetárias. In: LIMA, G. T.; SICSÚ, J.; DE PAULA, L. F. (Org.). Macroeconomia Moderna: Keynes e a Economia Contemporânea. Rio de Janeiro: Ed. Campus, 1999.

CARVALHO, F. C. Sobre a centralidade da teoria da preferência pela liquidez na macroeconomia pós-keynesiana. Ensaios FEE, Porto Alegre, v. 17, n. 2, p. 42-47, 1996.

CARVALHO, F. C. Temas de política monetária Keynesiana. Ensaios FEE, v. 15, n. 1, p. 33-61, Porto Alegre, 1994.

EVIEWS 8.0. Quantitative Micro Software, California. Copyright (C 2012. 
FREITAS, M. C. P. Banco Central Independente e coordenação de políticas macroeconômicas: lições para o Brasil. Economia e Sociedade, Campinas, v. 15, n. 2, p. 269-293, 2006.

GUJARATI, D. Econometria Básica. 4. ed. São Paulo: Makron Books, 2006.

INSTITUTO DE PESQUISA ECONÔMICA APLICADA. IPEA-DATA. Disponível em: <http://www.ipeadata.gov.br>. Acesso em: jun. 2016.

KEYNES, J. M. A Teoria Geral do Emprego, do Juro e da Moeda. São Paulo: Nova Cultural, 1985.

KEYNES, J. M. A Treatise on Money: the Pure Theory of Money - The Collected Writings of John Maynard Keynes. Londres: MacMillan: Royal Economic Society, 1971.

LIBÂNIO, G. A. Temas de política monetária: uma perspectiva pós-keynesiana. Textos para discussão, Belo Horizonte: UFMG: Cedeplar, n. 29, 2004.

MENDONÇA, H. F. Metas para a Taxa de Câmbio, Agregados Monetários e Inflação. Revista de Economia Política, v. 22, n. 1(85), jan./mar. 2002.

MODENESI, A. M. Regimes Monetários: Teoria e a Experiência do Real. Barueri: Manole, 2005.

MOREIRA, R. R. Revisitando as críticas pós-keynesianas à Nova Síntese Neoclássica: questões de política monetária. Análise Econômica, Porto Alegre, v. 30, n. 57, 2012.

OREIRO, J. L.; NEVES, J. L. O regime de metas de inflação: uma abordagem teórica. Ensaios FEE, Porto Alegre, v. 29, n. 1, p. 101-132, 2008.

SARAIVA, P. J.; DE PAULA, L. F. Crítica Pós-Keynesiana à Revisão do Novo Consenso Macroeconômico. In: ENCONTRO INTERNACIONAL DA ASSOCIAÇÃO KEYNESIANA BRASILEIRA, 7., 2014, São Paulo. Anais... São Paulo, 2014.

SICSÚ, J. A negação da ineficácia da política monetária: a alternativa de Keynes e dos pós-keynesianos. Análise Econômica, Porto Alegre, v. 15, n. 28, p. 80-107, 1997. 
SICSÚ, J. Políticas não monetárias de controle da inflação: uma proposta pós-keynesiana. Análise Econômica, Porto Alegre, v. 21, n. 39, 2003.

SILVA, G. J. C.; TERRA, F. H. B; VIANA, A. P. C. Uma Leitura Pós-Keynesiana da Dinâmica de Preços e da Política Monetária no Brasil Pós-Meta de Inflação: Uma Análise por Vetores Autoregressivos. In: ENCONTRO INTERNACIONAL DA ASSOCIAÇÃO KEYNESIANA BRASILEIRA, 7., 2014, São Paulo. Anais... São Paulo, 2014.

SUMMA, R. F.; MACRINI, L. Os determinantes da inflação brasileira recente: estimações utilizando redes neurais. Nova Economia, Belo Horizonte, v. 24, n. 2, p. 279-296, 2014.

TERRA, F. H. B. Uma interpretação pós-keynesiana do Regime de Metas de Inflação: poderia a Autoridade Monetária ser capturada pelo sistema bancário? In: ENCONTRO NACIONAL DE ECONOMIA POLÍTICA, 18., 2013, Belo Horizonte. Anais... Belo Horizonte, 2013.

\section{Como citar este artigo:}

\section{ABNT}

DEUS, Larissa Naves de. Dinâmica da inflação e política monetária no Brasil: uma leitura pós-keynesiana com uso da metodologia de Vetores Autorregressivos (VARs). RACE, Revista de Administração, Contabilidade e Economia, Joaçaba: Ed. Unoesc, v. 17, n. 1, p. 283-312, jan./abr. 2018. Disponível em: <http://editora.unoesc. edu.br/index.php/race>. Acesso em: dia/mês/ano.

\section{APA}

Deus, L. N. de. (2018). Dinâmica da inflação e política monetária no Brasil: uma leitura pós-keynesiana com uso da metodologia de Vetores Autorregressivos (VARs). RACE, Revista de Administração, Contabilidade e Economia, 17(1), 283-312. Recuperado em dia/mês/ano, de http://editora.unoesc.edu.br/index.php/race 